\title{
Discursos sobre Família e Risco nas Internações Compulsórias de Usuários de Drogas
}

\author{
Carolina dos Reis \\ Neuza Maria de Fátima Guareschi \\ Universidade Federal do Rio Grande do Sul \\ Porto Alegre, RS, Brasil \\ Salo de Carvalho \\ Universidade Federal do Rio de Janeiro \\ Rio de Janeiro, RJ, Brasil
}

\begin{abstract}
RESUMO
Este artigo tem por objetivo problematizar os discursos que produzem os modos normais e patológicos de se constituírem relações familiares que circunscrevem as famílias de jovens usuários de drogas e que são utilizados para dar legitimidade às intervenções do Estado, tendo como foco as internações compulsórias para tratamento por uso de drogas. Para isso, analisamos os processos judiciais de adolescentes que tiveram decretada a medida protetiva de internação psiquiátrica para tratamento por drogadição durante os meses de março a julho de 2011, em Juizados da Infância e da Juventude, em dois grandes municípios do estado do Rio Grande do Sul. A partir disso, problematizamos a forma como determinadas práticas de cuidado, circunscritas nos campos de saber da psicologia, do direito e da rede de assistência aos adolescentes usuários de drogas, inscrevem a família como um dos principais fatores de vulnerabilidade e risco desses jovens.
\end{abstract}

Palavras-chave: Família; Internação Compulsória; Usuários de Drogas; Adolescência; Sistema de Garantias de Direitos da Criança e do Adolescente.

\section{ABSTRACT}

\section{Discourses about Family and Risk in the Compulsory Hospitalization of Drug Users}

This article aims to problematize the discourses about the ways considered normal and pathological of being a family that circumscribe the families of the adolescents with detention for compulsory treatment for drug abuse. For such, we analyzed the lawsuits of adolescents that had been ordered the protective measure of psychiatric hospitalization for treatment for drug addiction, during the months from March to July 2011, in two major cities in the state of Rio Grande do Sul. We discussed how certain care practices, circumscribed in psychology's and law's fields of knowledge, in the adolescents drug users social and helf care services, indicates the family as the main risk and vulnerability factors for them.

Keywords: Family; Compulsory Hospitalization; Drug Users; Teenagers; Child and Adolescent Guarantees Rights System.

\section{RESUMEN}

\section{Discursos sobre Familia y Riesgo en Internamiento Forzoso de Usuarios de Drogas}

Este artículo tiene como objetivo problematizar los discursos que producen los modos normales y patológicas de constituir relaciones familiares que circunscriben las familias de los adolescentes con medida de internación obligatoria de tratamiento por consumo de drogas. Para esto, analizamos procesos judiciales de adolescentes en que había decretado la medida de protección de la hospitalización para el tratamiento psiquiátrico por la adicción a las drogas, durante los meses de marzo a julio de 2011 en dos grandes ciudades en el estado de Rio Grande do Sul. Con eso analisamos cómo ciertas prácticas de atención, circunscritas en los campos de conocimiento de la psicología y del derecho, en la red de servicios de atención a los usuarios de drogas, inscreven a la familia como un factor importante de vulnerabilidad y riesgo a estos jóvenes.

Palabras clave: Familia; Hospitalización obligatoria; Usuarios de drogas; Adolescencia; Sistema de Garantía de los Derechos del Niño y del Adolescente. 


\section{INTRODUÇÃO: ENTRE O PODER FAMILIAR E O PODER ESTATAL}

Este artigo tem por objetivo problematizar os discursos que produzem os modos normais e patológicos de se constituírem relações familiares que circunscrevem as famílias de jovens usuários de drogas e que são utilizados para dar legitimidade às intervenções do Estado, tendo como foco as internações compulsórias para tratamento por uso de drogas. Para tanto, tem como base o desenvolvimento de uma pesquisa que empreendeu a análise de processos judiciais de adolescentes que tiveram decretada a medida protetiva de internação psiquiátrica para tratamento por drogadição. No presente artigo, tomamos como operadores para esta análise as práticas da Psicologia, do Direito (e dos demais campos de saber que se aliam a estes primeiros, como a Pedagogia, o Serviço Social) vinculadas ao Sistema de Garantia de Direitos (serviços de saúde, assistência social, justiça, segurança pública, entre outros) que fornecem informações que orientam os processos judiciais, que circundam essa instituição "família".

A família é uma questão central nas ações relacionadas com a adolescência, uma vez que o que o está em jogo dentro dos processos é a destituição do seu lugar de gestão sobre a vida de seus membros e a tomada desse lugar pelo Estado, que assume em maior ou menor medida as funções de cuidar, educar e proteger. Entretanto, o que se evidencia na forma como o Estado vem ser convocado a tomar para si o poder familiar, nos processos judiciais de adolescentes usuários de drogas, é uma dupla relação que permite anunciar as falências de determinadas famílias, sem com isso pôr em risco as funções da "instituição familiar". Isto ocorre por meio de um jogo de produção dos modos normais e patológicos de constituírem relações familiares e um mecanismo de inscrição no interior das famílias da responsabilidade por problemáticas políticas, sociais e econômicas que extrapolam o âmbito privado.

Assim, neste artigo, em um primeiro momento, analisamos o modo como foram se constituindo as relações entre Estado e Família e de como o primeiro passa a tutelar esta visando o bom desenvolvimento e controle dos indivíduos e da sociedade. No segundo momento, trazemos as análises dos processos judiciais de internação compulsória para problematizarmos as estratégias das ações estatais que, embora ajam em nome da proteção dos jovens, operam produzindo estigmatizações e agravo nas condições de vulnerabilidade a que estão expostos as famílias e os jovens usuários de drogas.

\section{FUNDAMENTAÇÃO TEÓRICA: A FAMÍLIA COMO INSTRUMENTO DE GESTÃO DO ESTADO}

Para compreendermos o modo como a Família vai se constituir em um espaço de intervenção estatal nos aproximamos dos estudos de Foucault (2014), quando este analisa o desenvolvimento da arte de governar pelo Estado. O autor identifica a relação entre a Família e o Estado como um importante elemento no governo das populações. Até o final do século XVII, a Família constituía-se na menor organização política possível. Ela era sujeito e objeto de governo - sujeito nas relações de poder internas à Família e objeto na sua inserção dentro do campo político. O chefe de família era quem respondia por seus membros tanto no que se refere à sua proteção e sustento, quanto naquilo que diz respeito à manutenção desses sujeitos dentro dos limites da ordem social. A relação do Estado com a Família era a de que, na medida em que as famílias mantivessem seus membros dentro das regras de obediência, o Estado lhes daria suporte para que fizessem deles aquilo que lhes conviesse e, ainda, lhes proveria, caso fosse preciso, os meios necessários para que chamassem os seus membros à ordem (Donzelot, 1986).

Entretanto, ao final do século XVIII, com o crescimento populacional e a pauperização nas condições de vida, as Famílias já não conseguiam mais conter seus membros nos limites que lhes competia. As desordens ameaçavam a organização familiar burguesa e levavam a instituição Família à beira do descrédito. Se por um lado, a burguesia sentia-se ameaçada pelo descrédito da Família, por outro enfrentava o temor, igualmente significativo, da possibilidade de constituição de um Estado totalitário que assegurasse, talvez, as necessidades básicas de todos os cidadãos, mas à custa de uma possível redistribuição de renda. Assim, a questão que se colocava para a burguesia era de que forma convocar a intervenção do Estado junto a essa população pauperizada sem ameaçar a consolidação dos ideais liberais (Donzelot, 1986).

As práticas higienistas da época tiveram papel fundamental na construção de respostas a essa problemática ao incitar o Estado a intervir de modo a não provocar mudanças estruturais, mas provocá-las na esfera do direito individual, pela via da adaptação positiva e da adequação às normas sociais. Para tanto, acompanhou-se, nesse período, a emergência de estratégias de despolitização da Família. Essa despolitização veio, justamente, no sentido de transformar aquilo que se constituiria como algo da ordem de um direito político em uma questão moral 
e econômica. A Família foi direcionada para os problemas privados, como as relações conjugais, a sexualidade, a pedagogia das crianças e a adaptação social (Lemos, 2009).

A medicina social contribuiu, dessa maneira, para a construção desse modelo familiar moderno e para a constituição e fortalecimento de um determinado modo de organização e gestão do Estado. O governo deixou de agir sobre a Família e passou a operar através desta e sobre a população. A Família passou a constituirse em um instrumento privilegiado de governo das populações. Nesse novo modelo, sempre que o Estado quisesse produzir mudanças na população, era por meio das famílias que agia. As famílias tornaram-se focos de campanhas de vacinação e contra a mortalidade, bem como de questões relativas aos casamentos, dialogando diretamente com os interesses privados de seus membros (Foucault, 2014).

Para Reis (2012) a Psicologia vai se constituir também como uma aliada nos modos de governo sobre a Família. Para a autora as práticas psi vêm forjar a existência de uma interioridade nos sujeitos e a designam como fonte de doenças e desvios. A Psicologia, como portadora de um saber sobre o privado, emerge como uma ferramenta para intensificar as formas de governo das vidas. A Família enquanto aquilo que é exterior à interioridade do sujeito e que está em relação direta com este, vai se constituir como forma privilegiada de intervenção.

Dessa forma, foi possível ao Estado vir "em socorro" das famílias, tornando-se o responsável pelo seu bem-estar, não por uma condição que lhes é de direito, mas pela via do assistencialismo. Atrelada a isso, a contrapartida que se colocou à Família foi uma abertura ao Estado para recondução das normas na esfera privada. Atendendo aos interesses da burguesia, o Estado foi chamado a intervir em nome da ordem, junto à segurança pública e à justiça, garantindo a liberdade necessária ao exercício da violência, a partir da lógica de mercado. Essa será uma das formas de violência legitimadas socialmente, em detrimento de outras, destacadas como aquelas a serem combatidas.

$\mathrm{O}$ Estado, ao intervir junto à segurança pública, tratará da violência de forma individualizada como uma disfunção particular de uma e outra família e de seus membros. Essas famílias serão, então, esquadrinhadas como se nelas estivesse a possibilidade de reverter um quadro político e social disparador de processos de criminalização e insegurança. $O$ que vem dar legitimidade a esse modo de intervenção do Estado é o discurso técnico-científico, através do qual, modelos hegemônicos são reforçados como naturais, como o da família burguesa. Esse mecanismo, que privatiza os problemas sociais, concentra-se na enumeração das incompetências individuais frente às buscas de estratégias de sobrevivência no jogo de mercado e recai em uma lógica de culpabilização dos pobres pelo fracasso em ascender economicamente (Scheinvar, Nascimento, \& Lemos, 2014).

Nesse sentido, o que vai ser colocado em questão não é a função protetiva atribuída historicamente à instituição Família, nem a estrutura social que expõe determinadas famílias às condições de vulnerabilidade social, mas as falências individuais de cada grupo familiar no bom desenvolvimento de seu papel. Nascimento (2012), ao analisar os mecanismos de desqualificação da família pobre e de criminalização da pobreza, evidencia as estratégias de atualização do discurso da família desestruturada. Através de tais estratégias, as famílias pobres ganham estatuto de famílias negligentes. O que vai ser apontado não é a simples falta de condições financeiras da família para oferecer cuidado e proteção a seus membros, mas a forma como elas vêm violar os direitos fundamentais das crianças e adolescentes, privando-os do acesso a boas condições de moradia, saúde, educação, alimentação, etc. Para a autora, as situações de negligência e maus-tratos vão ser apontadas como incompetência familiar, sendo invisibilizadas nesse meio as questões estruturais do capitalismo neoliberal, que expõe esses sujeitos à privação de direitos. Por outro lado, dá-se visibilidade à violência como algo da ordem dos problemas individuais, criminalizando-se e demonizando-se as famílias pobres.

Vemos aí a construção de um novo contrato entre a Família e o Estado, o que permitirá a este último intervir. Entretanto, ele não irá intervir em qualquer família; ele vem "em socorro" das famílias pobres e, dentre essas, daquelas cuja pobreza não esconda nenhuma artimanha, pois, ao tornarem-se resilientes às normativas do Estado, precisam apresentar resultados que demonstrem melhorias nos seus modos de vida (Donzelot, 1986).

A medicina social e, posteriormente, as ciências psi e pedagógicas vão produzir "métodos modernos" de criação e educação das crianças. Há uma proliferação discursiva prescrevendo como os pais devem cuidar de seus filhos. Na mesma medida em que esses campos de saber constroem uma nova noção de desenvolvimento saudável, afirmam inversamente aquilo que constitui os modos patológicos de ser criança e adolescente e os agentes responsáveis por esse adoecimento. Dentro disso, alertam para os riscos inerentes à criação de crianças e adolescentes em ambientes economicamente desassistidos, relacionando-os, principalmente, ao desenvolvimento de comportamentos delinquentes. 
Contemporaneamente, ao analisarmos os processos judiciais de crianças e adolescentes usuários de drogas, evidenciamos a atualização dos mecanismos de culpabilização da família por questões que expolam o âmbito privado e se constituem como problemáticas sociais, mas que ao serem expressas no interior dos processos, emergem como deteriorações genéticas, sanitárias, sociais, morais e psicológicas. Essas descrições têm em comum o fato de serem apresentadas como justificativas que fundamentariam a necessidade de intervenção do aparelho tutelar do Estado sobre as famílias pelos supostos riscos que estas oferecem ao desenvolvimento dos jovens, colocando-os em uma trajetória considerada como de risco ou potencialmente perigosa.

Nesse sentido, evidencia-se a importância de colocar em análise os discursos produzidos no interior da "rede de proteção", denunciando o caráter despolitizador que assumem ao encerrar no âmbito familiar privado a problemática do uso abusivo de drogas por adolescentes. Essa ação reforça os discursos que sustentam as práticas de internamento compulsório como sendo alternativa prioritária para o tratamento de jovens usuários de drogas, dado a falência do suporte familiar e a necessidade de afastamento dos jovens desse ambiente considerado produtor de desvios e degenerações, mantendo legitimado um modo hegemônico de ser família.

\section{PROCEDIMENTOS METODOLÓGICOS}

Para colocar essas questões em discussão, partimos de uma pesquisa que analisou os processos judiciais de adolescentes que tiveram decretada a medida protetiva de internação psiquiátrica para tratamento por drogadição, oriundos de dois municípios do Rio Grande do Sul. Foram analisados 14 processos judiciais de sujeitos maiores de 12 anos e menores de 18, tanto de meninos quanto de meninas, durante os meses de março a julho de 2011. Os trechos dos processos que serão apresentados ao longo do estudo sofreram modificações para evitar a identificação dos casos, preservar a identidade dos adolescentes e familiares e respeitar o segredo de justiça.

Da mesma forma, buscamos preservar a identidade dos profissionais, omitindo as especificidades das instituições envolvidas e dos municípios em que os materiais foram coletados. O critério que balizou a quantidade de processos analisados foi a saturação dos dados. Esse foi um critério que emergiu durante a análise dos processos e por si só representa um importante analisador. Apesar de cada jovem possuir uma história de vida absolutamente singular, ao olhar para os Processos Judiciais, essa singularidade se perde, e a sensação é de que estamos sempre diante do mesmo adolescente.

Isso remete a perguntas como: o que esses Processos Judiciais fazem falar a respeito desses adolescentes? Que tipo de práticas eles mobilizam em torno dessa população?

Nesse sentido, ao analisarmos esses documentos, buscamos identificar as relações que se estabelecem entre os campos de saber e os mecanismos de poder que incidem sobre a manutenção de certas verdades ditas sobre as famílias de adolescentes usuários de drogas, as quais vão servir de suporte para a legitimação e atualização da estratégia de internação compulsória. Em especial, buscamos destacar as articulações estabelecidas entre os campos da Saúde e da Justiça que dão fundamento a processos de desqualificação e destituição das famílias frente à "rede de proteção" estatal e as formas de cuidado compulsoriamente exercidas por essa. Ao aprofundarmos nosso olhar sobre os conteúdos dos autos processuais e dos documentos que os compõem, observamos a existência de uma relação estratégica entre os campos jurídico, psiquiátrico e pedagógico, que se somam na constituição da "rede de proteção" que circunscreve os diversos aspectos da vida dos adolescentes. Acompanhando as escritas dos documentos, buscamos problematizar essa oferta de proteção e cuidado a partir das contradições que permeiam a manutenção dos discursos sobre a proteção no interior dos materiais de pesquisa.

\section{PROCEDIMENTOS E ANÁLISES DOS MATERIAIS}

\subsection{As portas de entrada}

Os Processos Judiciais em questão, de maneira geral, iniciam por ação da Defensoria Pública ou do Ministério Público (MP) - Promotoria da Infância e da Juventude. No primeiro caso, a própria família do adolescente busca voluntariamente auxílio da justiça para internação do adolescente. Essa busca é considerada necessária pela família, ou porque o adolescente se nega a aceitar o tratamento, ou porque, ainda que o adolescente o aceite, a família não encontra vaga ou local adequado para atendimento na rede de saúde do seu município. A entrada se dá por meio da Defensoria Pública pela impossibilidade de contratar um advogado particular sem prejudicar a sobrevivência familiar, o que geralmente é comprovado por demonstrativos de renda e atestados de desemprego.

No segundo caso, o MP, enquanto órgão responsável pela proteção dos direitos difusos, coletivos, individuais homogêneos e das crianças, adolescentes, idosos, 
indígenas e considerados incapazes, quando diante de alguma denúncia de violação de direitos, pode acionar a Justiça em prol da defesa desses. Em geral, situações de violação de direitos chegam ao MP através do Conselho Tutelar (CT) ou de outros serviços da rede de saúde e assistência social. Além disso, ainda que a ação tenha sido ajuizada pela Defensoria Pública, também é obrigatória a intervenção do Ministério Público, sob pena de nulidade do Processo.

Apesar da presença de ambos nessa segunda hipótese, uma diferença significativa nas duas portas de entrada é a de que, pela Defensoria Pública, os familiares costumam buscar o auxílio do Estado, assumindo a falência do seu papel protetivo em relação aos seus membros. Já os processos que são originados no Ministério Público usualmente são movidos pelo Conselho Tutelar, e não pela família; é o Conselho Tutelar ou outro serviço da rede pública que está afirmando a falência da família e a necessidade de intervenção do Estado.

\subsection{Abrindo os Autos}

\section{Petição Inicial}

Quando abrimos os autos do Processo Judicial, deparamo-nos com seu conjunto de peças. A primeira delas, a petição inicial, expedida pela Defensoria Pública ou Ministério Público, é composta por três partes: a exposição dos fatos, a exposição dos direitos e a exposição dos pedidos.

a) Exposição dos fatos. A exposição dos fatos consiste em algo como a construção do caso ou, talvez, a caracterização das situações de vida na forma de um caso. É o resumo de determinados pontos das narrativas da vida do adolescente e de sua família naquilo que os torna objeto de ação da Justiça e do Estado. São destacados relatos de violações de direitos presentes na história de vida dos sujeitos. Portanto, quando questionamos o que esses Processos Judiciais fazem falar sobre os adolescentes, eles fazem falar das violências, negligências, abandonos, agressões, ausências, falências, abusos e delitos que justificam a inserção dessa família no Sistema de Justiça e, mais do que isso, que justificam sua inserção nas múltiplas instituições de proteção do Estado, que compreendem a assistência social, saúde e educação, entre outras. Em geral, essa primeira parte da petição inicial contém trechos retirados de forma literal e deslocada do contexto do interior de pareceres e relatórios de médicos, psicólogos, conselheiros tutelares e assistentes sociais, que servem para marcar o quanto é imprescindível e inadiável a intervenção do Judiciário junto àquele sujeito e àquela família.
É interessante pensarmos que esse trecho da petição se intitula "exposição dos fatos": enuncia-se logo na abertura dos autos uma suposta verdade sobre os adolescentes na forma de fatos. Vejamos alguns deles:

O jovem é dependente químico, faz uso de crack abusivamente, potencializando seu comportamento agressivo. Além disso, subtrai objetos para vender e adquirir drogas. Seu estado é de total descontrole, colocando em risco sua vida e de seus familiares. A convivência familiar é insuportável, pois a guardiã não pode sair de casa para impedir que o jovem venda seus pertences. Segundo a guardiã, o jovem fica agressivo quando não tem dinheiro para comprar drogas. Quando sob efeito da substância, fica extremamente violento e agressivo com familiares, fazendo ofensas verbais e agressões fisicas. O jovem não aceita tratamento voluntário, diz que não é usuário de drogas. Embora não reconheça que está em estado de desesperança e extrema necessidade, quadro de extremo descontrole, teme-se pela vida dele e de outras pessoas que residem em sua casa. É imprescindivel a internação para tratamento, definição de diagnóstico e avaliação neurológica, e, depois de realizada a devida desintoxicação, o encaminhamento a local destinado à recuperação de drogados.

O retrato construído é de violência, agressão e falta de controle, com a família em estado de total desespero, sem saber como agir e pedindo auxílio do Estado. Alerta-se para o início de ações delituosas, como a subtração de objetos da família. Constrói-se a noção de risco não somente de vida desse jovem, mas, mais do que isso, de um risco que ainda é possível restringir ao espaço da família, mas que pode potencialmente alastrar-se para o espaço público.

Estavam as jovens na casa de acolhimento por negligência do genitor. Desde o final de 2007, estavam em situação de rua, mendicância e uso compulsivo de crack. Em casa, eram agredidas pela genitora, também dependente química. Foram internadas, e depois retornaram para a rua, sem continuidade do tratamento ambulatorial. $\mathrm{O}$ acolhimento institucional, como medida de proteção, tem buscado promover reinserção na família paterna, sem êxito, em função do vício que faz com que retornem para rua. O plano de atendimento indica necessidade de tratamento para desintoxicação em Comunidade Terapêutica pelo período mínimo de seis meses e, após, retorno para 
casa dos avós. Ambas as jovens já foram tratadas em CAPSi, o que demonstrou ser insuficiente.

Neste segundo caso, observa-se o relato da falência familiar, o ambiente da casa das jovens como um espaço para elas insuportável que as levou às ruas e ao uso de drogas. A família entra como o elemento impulsionador dessas jovens para a situação de uso. No entanto, ela não é o foco da intervenção; busca-se um tratamento para o uso de drogas, algo que, nesse relato mesmo, aparece como sintoma, e não como causa.

São fatos apresentados, muitas vezes, de maneira contraditória; em outras, de forma bastante precária ou pouco consistente nas argumentações. Isso é um indício de que os trechos retirados de documentos emitidos por psicólogos e outros trabalhadores sociais, utilizados para dar sustentação a esses fatos, estão aí cumprindo uma função que é menos técnica e mais moral.

b) Exposição dos direitos. É a nomeação dos direitos que estão sendo violados e precisam ser garantidos. Nessa parte são citados o direito à saúde e alguns trechos da Constituição Federal e do Estatuto da Criança e do Adolescente que dão sustentação legal à ação interventiva que se espera alcançar.

\section{Constituição Federal - 1988}

Art. 227. É dever da família, da sociedade e do Estado assegurar à criança, ao adolescente e ao jovem, com absoluta prioridade, o direito à vida, à saúde, à alimentação, à educação, ao lazer, à profissionalização, à cultura, à dignidade, ao respeito, à liberdade e à convivência familiar e comunitária, além de colocá-los a salvo de toda forma de negligência, discriminação, exploração, violência, crueldade e opressão. (Brasil, 1988) (Petição Inicial)

\section{Estatuto da Criança e do Adolescente - 1990}

Art. $7^{\mathrm{O}} \mathrm{A}$ criança e o adolescente têm direito à proteção, à vida e à saúde, mediante a efetivação de políticas sociais públicas que permitam o nascimento e o desenvolvimento sadio e harmonioso, em condições dignas de existência. (Brasil, 1990a) (Petição Inicial)

O contraditório de o Art. 227 da Constituição Federal ser utilizado para justificar a garantia do direito à saúde por meio da internação compulsória é que essa forma de proteção à saúde coloca em risco a manutenção de outros direitos, como o direito à liberdade e à convivência familiar e comunitária. Afirma-se com isso a existência, dentre esses direitos, de um "bem maior" que seria a manutenção da vida biológica, a despeito das formas de discriminação, violência, crueldade e opressão que podem estar advindo com ele no interior mesmo dessa ação de internação compulsória. Se a questão aqui fosse unicamente a garantia dos direitos constitucionais, deveríamos estar falando, tal como referiu Xavier (2012), em programas de: moradia compulsória, emprego compulsório, alimentação compulsória, cultura compulsória e lazer compulsório. A saúde é um direito, mas a internação compulsória não; ao contrário, configura-se, para esses adolescentes, antes como um dever.

Outra questão importante de ser destacada em relação ao modo como é apresentada a petição inicial é a da cisão entre a exposição dos fatos e dos direitos. Essa diferenciação evidencia a distância presente entre o "ser" e o "dever ser", isto é, a distância entre as situações descritas como aquelas vivenciadas pelos jovens e os direitos que a estes deveriam ser assegurados. Vemos aqui a presença de uma abordagem na qual os direitos estariam dissociados da vida cotidiana, por isso se justifica a necessidade de exposição dos direitos como se somente a exposição dos fatos não oferecesse fundamentos suficientes para justificar os pedidos expostos a seguir. Diante disso, caberia ao juiz decidir se essas duas esferas devem permanecer distantes ou se deveriam ser aproximadas.

c) Exposição dos pedidos. A exposição dos pedidos refere-se ao que se quer com a ação. Aqui é solicitado ao Judiciário:

Requere-se internação compulsória com utilização de reforço policial, se necessário. Após, encaminhamento para casa de recuperação de drogaditos pelo período de, no mínimo, seis meses, podendo-se fazer uso da força policial, se necessário. O paciente deve ficar sob custódia médica até recuperação. (Petição Inicial)

Destaca-se, na exposição dos pedidos, o reconhecimento da possível necessidade de uso da força policial. O efeito desse tipo de reconhecimento é o de circunscrever esse adolescente no lugar de um sujeito que oferece perigo, mas é também um vestígio que denuncia uma ação autoritária de restrição da liberdade sendo exercida sobre esses sujeitos.

A produção desses textos vem fundamentada pela fala de especialistas psi e de outros trabalhadores sociais que, aliados, potencializam o efeito moralizador dos saberes e instituições. Ao falarmos em moralização, atentamos para a não neutralidade das produções das ciências, para as suas articulações éticas e políticas 
com outros atores sociais que mantêm determinados discursos em ascensão em relação a outros. Em última instância, quem proporciona fundamentos para sustentar a afirmação desses sujeitos e de suas famílias como aqueles que oferecem risco são as ciências $p s i$ e sociais, e o judiciário vai agir com base nesse suporte. Dá-se aí o entendimento de que não é somente o Judiciário que interna os jovens: é uma rede de atores que, quanto mais articulada, mais legitimada permanece.

\subsection{Atestados de veridicidade}

\subsubsection{Pareceres de especialistas}

A seguir, na pesquisa com os processos judiciais, encontramos uma série de documentos que buscam demonstrar a suposta verdade sobre a realidade de vida em que se encontram o adolescente e a família. Através desses documentos, quer-se atestar a necessidade de intervenção do Judiciário em cumprimento dos pedidos apresentados na petição inicial.

São esses elementos que fornecerão informações ao juiz; eles compõem a instrução do processo. São relatórios, pareceres, laudos e estudos sociais dos especialistas que já estiveram envolvidos com essa família. Esses materiais indicam a falência dos cuidados oferecidos de forma extrajudicial. Em geral, esse enunciado dá-se não por dificuldades da rede de serviços, mas pelo suposto grau de comprometimento dos sujeitos em questão.

Veem-se:

1. Relatórios mensais/quinzenais de serviços de abordagem de rua;

2. Documentos do Conselho Tutelar;

3. Declarações de Conselhos de Defesa dos Direitos da Criança e do Adolescente sobre a necessidade de internação e intervenção do Estado junto ao adolescente e à família;

4. Termos de reuniões realizadas no Ministério Público com diversos serviços da rede de proteção;

5. Oitiva de profissionais da rede de saúde, assistência social e segurança pública junto ao MP;

6. Relatórios mensais de acompanhamento de Abrigos;

7. Atestados de Matrícula;

8. Relatórios das Escolas;

9. Fichas de Comunicação de Aluno Infrequente (FICAI);

10. Pareceres de Clínicas Psiquiátricas;

11. Laudos periciais das Clínicas e Hospitais Psiquiátricos em que ocorrem as internações;

12. Comunicados de Internação Involuntária em Clínicas e Hospitais Psiquiátricos;
13. Laudos médicos dos serviços de pronto atendimento indicando a necessidade de internação.

14. Pareceres Psiquiátricos;

15. Pareceres Psicológicos;

16. Avaliação Social;

17. Estudo Psicossocial das equipes das instituições de abrigamento e de equipes do próprio Judiciário;

18. Relatório de Equipe Interprofissional do Juizado da Infância e da Juventude;

19. Relatórios das Secretarias de Saúde e de Assistência Social;

20. Relatórios dos Centros de Atenção Psicossocial modalidade infantil;

21. Ofícios das Secretarias e Coordenadorias de Saúde e Assistência Social;

22. Sistema de Informação de Agravos de Notificação (SINAN);

23. Ficha do cadastro nacional de adoção de filhos de adolescentes usuárias de drogas;

24. Ofícios dos hospitais e clínicas de internação comunicando abandono das famílias;

25. Guias de acolhimento institucional em abrigos por abandono das famílias nas clínicas e hospitais psiquiátricos;

26. Declaração dos abrigos de evasão dos adolescentes e retorno para as ruas.

\subsubsection{Ocorrências policiais e consultas}

A seguir, encontramos consultas sobre os adolescentes junto à Secretaria Estadual de Segurança Pública do Rio Grande do Sul. Nessas consultas, são encontrados registros como:

a) Abandono de incapaz;

b) Abandono material;

c) Aborto;

d) Ameaça;

e) Atentado violento ao pudor/Ato obsceno;

f) Desaparecimento do abrigo (muitos);

g) Lesão corporal;

h) Pronto Atendimento na Delegacia Especial da Criança e do Adolescente (DECA) por pequenos furtos.

Ainda, são feitas consultas ao Tribunal de Justiça, sendo elencados registros de:

i) Lesão corporal (ato infracional);

j) Medidas Protetivas (abrigamentos, inclusões em programa de apoio, tratamento e orientação);

k) Destituições do Poder Familiar;

Além disso, são consultados os endereços informados pelas famílias ou pelos serviços. A consulta de endereços é comumente feita através das empresas de 
telefonia móvel e tem por objetivo auxiliar na localização dos adolescentes e das famílias para verificação, por parte do Conselho Tutelar, das condições de vida da família, bem como para localização do adolescente pelo Oficial de Justiça quando da expedição do mandado de busca e apreensão.

Permanecemos aqui diante de registros de violações de direitos sofridas e protagonizadas por esses adolescentes que os vão incluindo na malha da saúde, justiça, segurança pública e assistência social, todas elas operando em nome da proteção, do cuidado e da salvaguarda aos direitos da criança e do adolescente.

\subsubsection{Audiências}

Encontramos o relato das audiências realizadas com a família, adolescentes ou profissionais da rede de serviços de saúde ou assistência social. Em rede de serviços, incluem-se os Conselhos de Defesa dos Direitos da Criança e do Adolescente, Conselhos de Combate à Exploração do Trabalho Infantil, Prefeituras Municipais, Secretarias de Saúde, Assistência Social e Educação, Serviços de Saúde, como Centros de Atenção Psicossocial Infantil, Clínicas e Hospitais Psiquiátricos, Secretarias de Assistência Social, Serviços de Abordagem de Rua e Abrigamento, Conselhos Tutelares, Delegacia Especial da Criança e do Adolescente, Departamento de Investigação de Narcotráfico, Secretarias de Turismo, Indústria e Comércio (chamadas quando há situações que possam perturbar comerciantes ou em questões relacionadas à exploração de mão de obra infantil).

As audiências com a família e com os adolescentes merecem um destaque especial, posto que o papel a eles delegado nesses momentos é bastante restrito. A família, como já salientava Donzelot (1986), comparece à audiência por hábito de submeter-se às convocações, mas certamente não para desempenhar qualquer papel; afinal, é por causa dela que o adolescente se encontra naquela situação. A autoridade familiar já foi destituída pela presença do juiz, e a possibilidade de oferecer explicações pautadas pela razão é conferida aos especialistas $p s i$ e outros técnicos sociais, logo, resta à família o lugar da deferência, da súplica, da confissão ou da desistência.

Alguns relatos de audiências com familiares são encerrados com a seguinte frase: "Foram esclarecidos sobre o que poderá acontecer". Um leitor desavisado ficaria pensando: o que poderá acontecer? Certamente, os autos do processo não são para ser lidos por sujeitos desavisados, mas por aqueles que têm clareza sobre o que poderá acontecer às famílias que não se sujeitarem às normas legais e sociais expressas naquele dispositivo da audiência.
$\mathrm{O}$ adolescente-sujeito a ser protegido, por outro lado, é tratado nessas audiências como "réu"/"acusado" e, em geral, está sozinho no Processo. A audiência, para ele, serve como o momento de testar seu caráter: ou admite tudo que dizem e como dizem os técnicos a seu respeito, ou estará atestando que é um jovem dissimulado, incapaz de reconhecer seus atos. De qualquer forma, será objeto das medidas consideradas cabíveis pela rede de proteção ou, em outras palavras, "daquilo que poderá lhe acontecer".

\subsection{Decisão do Juiz}

Não poderíamos deixar de fazer referência à decisão judicial, que supostamente seria o momento mais esperado do Processo. Dizemos supostamente porque é preciso destacar que os Processos em questão nesta pesquisa se destinam à determinação judicial, ou não, da medida protetiva de internação compulsória para tratamento por uso de drogas. Entretanto, o que ocorre é que, no transcorrer do Processo, geralmente os jovens acabam entrando e saindo de diversas internações psiquiátricas para tratamento contra a drogadição por outras vias, tais como: (1) a internação involuntária (mobilizada por familiares ou por algum serviço de saúde ou assistência social - nesses casos, os jovens são levados para internação, mesmo contra sua vontade, quando avaliada a necessidade frente ao risco de vida iminente para o jovem ou para aqueles que o cercam); (2) a busca espontânea, quando os jovens são convencidos por esses serviços ou familiares a buscar espontaneamente as emergências psiquiátricas e são então encaminhados para internação; (3) levados para internação pela Brigada Militar.

Apesar das internações, o que costuma ocorrer é o retorno desses jovens ao uso de drogas e a manutenção do Processo pelo entendimento do Ministério Público, da Defensoria ou de outros profissionais que oferecem atendimento a esses jovens de que seriam necessárias novas internações. Nesse sentido, quando a sentença do juiz é pronunciada, ela acaba somando-se a mais uma dessas várias internações pelas quais os jovens já passaram, ou, nas raras ocasiões em que são negados os pedidos de internação, essa será somente uma internação a menos, mas elas não deixarão de ocorrer por essas demais vias.

Ao fazermos essa análise, estamos indicando o efeito que essa decisão acaba tendo de forma mais direta no cotidiano dos jovens, mas não podemos ser ingênuos em relação à importância desse parecer final no Processo Judicial e aos possíveis efeitos que pode representar quanto às práticas profissionais dos atores do Sistema de Garantias e das redes de saúde e assistência social. Isso porque é a sentença do juiz 
que indicará o caminho da verdade sobre os fatos e as formas de intervenção mais legitimadas para governar a vida desses jovens.

\subsection{Mandado de Busca e Apreensão ou de Condução Coercitiva para Tratamento}

Por fim, no que se refere aos documentos que são comuns à grande maioria dos Autos Processuais, temos o Mandado de Busca e Apreensão dos adolescentes, com condução à avaliação médica e, se indicado pelo médico, posterior encaminhamento para internação psiquiátrica em clínica ou hospital especializado.

A internação compulsória é aplicada aos casos de toxicomania por entorpecentes ou inebriantes quando provocada necessidade de tratamento ou quando for conveniente à ordem pública. Defere medida de cautela enquanto durar os sintomas; avaliação médica; mandado de condução coerciva com urgência e com auxílio da força pública; o laudo médico deve ser submetido ao juiz para avaliar internação. (Trecho de um Mandado de Busca e Apreensão)

Diante de um "direito" garantido coercitivamente, podemos pensar na possibilidade de defesa desses sujeitos por meio de um Habeas Corpus que garanta a compulsoriedade de outro direito seu: a liberdade. O esdrúxulo reconhecimento de que a internação é de fato uma prática punitiva e uma medida de restrição de liberdade abriria ironicamente mais possibilidades de defesa a esses adolescentes. Logo, evidenciamos que pode haver aí uma suspensão de direitos desses adolescentes frente à insígnia da sua proteção.

\subsection{Certidão do Oficial de Justiça}

Após o cumprimento do Mandado de Busca e Apreensão, é expedida uma certidão do oficial de justiça informando o juiz sobre o resultado de sua ação. Em muitas dessas certidões, fica evidente o quanto esses Processos Judiciais são descolados da situação de vida dos jovens, inclusive temporalmente. São situações que mostram as contradições entre os relatos expressos nos autos do processo e a situação encontrada pelo oficial quando do cumprimento do mandado para condução dos adolescentes para internação.

Na data da execução do mandado, o menino estava em outro município visitando a mãe. (Trecho de uma Certidão de Oficial de Justiça)

Certifico que o adolescente não estava na rua como informado, estava morando na casa do pai, frequenta o EJA, trabalha como aprendiz na empresa do pai e não necessita de internação. Devolvo o mandado para apreciação. (Trecho de uma Certidão de Oficial de Justiça)

É interessante ressaltar que, em muitos processos, esse ciclo de documentos se repete expressivamente, resultando em muitos Mandados de Busca e Apreensão e, por consequência, muitas internações psiquiátricas sem que nenhuma delas consiga pôr fim a esses Processos. Forte indicativo de que não é o uso de drogas o objeto de intervenção: esse é somente o pretexto que insere esse sujeito na dita "rede de proteção".

\section{DISCUSSÃO DOS RESULTADOS: A EXPOSIÇÃO DAS FALÊNCIAS FAMILIARES}

Após termos examinado o modo como são formulados e organizados os materiais que compõem os Autos Processuais e os efeitos que estes produzem na fabricação de verdades, passamos agora para um olhar mais atento ao conteúdo expresso no interior desses documentos. Nessa análise, debruçamo-nos sobre os discursos da Psicologia e do Direito presentes nos Processos Judiciais que circundam a instituição "Família".

Os pais dos meninos estão separados. As crianças vivem em precárias condições de moradia, casa com apenas uma peça, local úmido, com muitos ratos . A mãe tem dificuldade de cuidar de si e dos filhos, é soropositivo e está debilitada.

A mãe posiciona-se de forma contrária a transferência da guarda para a família paterna. $\mathrm{Na}$ avaliação da equipe, a mãe teme perder a pensão. Diante dessa possibilidade, a mãe mostra-se agressiva, fazendo ameaça à integridade dos filhos e dos profissionais da Assistência Social.

O pai dos meninos está "comprometido com o álcool". (...) A mãe já foi até o local onde os filhos se encontram e fumou crack com eles. Ela aparece lá esporadicamente para lhes pegar dinheiro. Mãe prostitui-se e mantém relação de ganhos financeiros com os filhos. (Relatório do Serviço de Abordagem de Rua da Assistência Social)

A mãe tinha um relacionamento extraconjugal com o pai de um dos seus filhos que não residia com ela. A família materna descrevia o relacionamento do casal como conturbado e com episódios de 
violência doméstica contra a mãe, assistidos pelos filhos. (Parecer do Abrigo - Assinado por Psicólogo, Assistente Social e Coordenação)

Há, ainda, outros casos, em Processos promovidos pela Defensoria Pública, com pais descritos como: sem controle sobre os filhos, que não conseguem estabelecer limites, impotentes, mal tratantes, negligentes, usuários de drogas, apenados, omissos, pobres, de vida desregrada, sem unidade conjugal, traficantes, desempregados, que perpetram abandono, que não estimulam o bom desenvolvimento, que vivem em precárias condições socioculturais, que necessitam de supervisão do Conselho Tutelar, pais em estado desesperador, incapacitados de tomar conta da situação em que os filhos se encontram, desorganização/desestruturação familiar, vitimados, com medo dos filhos e, claro, ausência paterna.

No que se refere às questões morais, observa-se sua articulação com afirmações higienistas que se organizam em torno do controle da sexualidade e da reprodução.

Com a morte dos pais, uma das irmãs foi para uma família acolhedora; já a outra ficou perambulando da casa dos avós para a casa de desconhecidos, amigos e namorados. Por fim, ficou grávida de um suposto namorado, que não se apresentou à família. (Relatório do Abrigo)

A genitora encontra-se bastante debilitada em decorrência da AIDS. Vizinhos relatam que tem comportamento promíscuo. Há suspeitas de que ela exponha as crianças às suas atividades sexuais. (Ofício do Conselho Tutelar)

Poderia citar, também, o processo aberto pela Promotoria em defesa do feto contra a mãe usuária de crack que reúne esses diversos elementos em sua descrição, sendo caracterizada como uma pessoa de "vida desregrada, solteira, sem endereço fixo, vitima de violência doméstica perpetrada por um exnamorado, mulata, agressiva, que vive em péssimas condições de higiene, sem documentos de identificação, negligente com os cuidados em relação ao filho, não realizou pré-natal, é omissa, coloca sua vida em risco, mente e não possui condições de assumir a guarda do filho quando do nascimento deste. Relata que possui histórico familiar de maus tratos e convivência com mãe que também era usuária de drogas e que já foi destituída de outra filha". A criança é abrigada logo após o nascimento e é efetivada a destituição do poder familiar. Bebês como esses, já apelidados de "filhos do crack", na maioria, são filhos de adolescentes usuárias de drogas que vivem em situação de rua e que são monitoradas pelos serviços de saúde e assistência até darem entrada no hospital para o nascimento do bebê. Nesse momento, em geral, são feitas diversas intervenções no sentido de a mulher só sair do hospital com o bebê se aceitar ser internada ou abrigada. Do contrário, o que muitas vezes acontece, o bebê acaba sendo abandonado no hospital ou entregue à adoção. O que está naturalizado e que se busca prevenir nessa situação é a composição de mais uma família negligente, de mais um sujeito a ser criado para cair nas malhas da criminalidade.

A lógica que fundamenta a promoção de estratégias biopolíticas como as citadas acima é a da prevenção ao risco. Isto é, ainda que não seja possível determinar com certeza o destino de um bebê fruto da gravidez não-planejada de uma adolescente usuária de drogas, os campos de saber, dentro de uma perspectiva positivista, oferecem fatores de "cálculo" sobre as possibilidades de vida desse bebê que podem direcioná-lo à delinquência. Lemos, Nascimento e Scheinvar (2010) alertam para o fato de que o conceito de risco tem sido considerado referência para embasar políticas públicas de governo sobre as condutas. A noção de risco, tomada como um objeto previsível e quantitativo, oferece a possibilidade de construção de medidas estatísticas à população que acabam por construir o risco como um fato passível de ser prevenido. Os debates acerca do risco, atrelados à proliferação de um sentimento de insegurança generalizado que baliza os modos de vida na sociedade contemporânea, aumentam a demanda por mecanismos de segurança.

Os saberes científicos, principalmente aqueles das ciências médicas e psicológicas, vão auxiliar na identificação desses elementos de risco. A noção de grupos de risco é um efeito disso, uma vez que, a partir da identificação de determinados sujeitos em meio à massa populacional, foi e continua sendo possível a execução de intervenções que adquirem um caráter de controle social e de cunho moral. Assim, essas estratégias de controle vão se exercer não somente sobre os corpos individuais, mas também sobre os grupos populacionais reconhecidos como de risco. Isso representa uma sofisticação nas técnicas no campo do controle do crime.

Young (2002) analisa esse deslocamento que passa do controle da criminalidade e do uso de drogas a partir de um sujeito distinto, com sua causalidade distinta, para a construção de ferramentas de controle sobre o conjunto da população. Para o autor, essas ferramentas vão implicar a produção de medições e cálculos estratégicos que avaliarão: os fatores responsáveis 
pelo aumento no uso de drogas e da criminalidade, as prioridades de intervenção do Governo, os diferentes efeitos e significados que as penalidades terão para cada grupo populacional, os deslocamentos populacionais gerados a partir de uma dada intervenção e, com eles, das taxas de criminalidade, entre outros.

Garland (2008) afirma que atualmente os agentes de controle do crime precisam falar o idioma econômico do custo/benefício. Segundo o autor, os custos do crime são rotineiramente calculados, como também o são os custos de sua prevenção, do policiamento e dos regimes prisionais. Esse modo de pensamento gera, para o campo criminológico, efeitos na própria forma como o sistema pensa o crime e o criminoso, "incentivando uma concepção de dano social mais baseada no custo e uma concepção do criminoso que enfatize a escolha e o cálculo racionais (p. 397)", portanto, passíveis de serem previstas e calculadas. A abordagem gerencial do crime tem como foco a prevenção em desfavor da punição e a minimização dos riscos à salvaguarda da justiça.

Young (2002) ressalta, ainda, que o florescimento de tecnologias cada vez mais sofisticadas para o manuseio atuarial da população ampliou a abrangência das ações de controle social. Dentro da lógica preventiva, essas ações vão ter como foco não somente as populações de risco, mas a totalidade da população. Elas operariam como uma "máquina branda" de controle social que se distribuirá pelas diversas instituições, em especial nos espaços de trabalho, onde se terá a organização da distribuição de recompensas associadas a milhares de pequenos transtornos punitivos. Se o crédito é o aspecto central nos modos de vida contemporâneos, a promoção da insegurança econômica leva os sujeitos a modificarem seus comportamentos para poderem manter-se no mercado de trabalho e ter acesso a melhores condições financeiras. "A demonização de outros, a criação de demônios populares e de pânicos morais é assim uma possibilidade sempre presente" (Young, 2002, p.279) que auxilia na ampliação do assujeitamento a essas estratégias de controle: é para diferenciar-se dos sujeitos reconhecidos como delinquentes, perigosos, desviantes, que os demais se submetem à dinâmica de mercado. Veem-se aí as articulações políticas, econômicas e sociais que se vinculam ao reconhecimento dos jovens usuários de drogas como uma população de risco.

Todas essas ferramentas de controle - as que incidem sobre os sujeitos individuais, aquelas destinadas aos grupos de risco e essas que agem sobre a totalidade da população - não são excludentes entre si; pelo contrário, elas coexistem e se potencializam. É preciso considerar que os cálculos dentro do controle do crime não se restringem ao mero fator monetário, mas implicam uma economia de valores morais e políticos. A adoção de uma guerra às drogas, por exemplo, seria contraditória a essa lógica, pois é excessivamente onerosa e de eficácia duvidosa. Entretanto, outro fator coloca-se no cálculo, que é a construção da imagem do perigo em torno dos sujeitos que se vinculam às drogas.

Nesse sentido, embora as ciências psi emirjam como portadoras de um saber que fala em nome da proteção dos adolescentes é por meio deste que é possível reconhecê-los precocemente como portadores de certos níveis de periculosidade. Se o Estado e os Operadores do Direito vão mobilizar intervenções sobre essa população, é a Psicologia e os demais trabalhadores sociais que oferecerão os indicadores de risco sobre os quais aqueles devem intervir. Para além disso, é sobre os fatores de risco apontados pelo conhecimento produzido pelas ciências psicológicas que incidirão as estratégias de prevenção que proliferam no campo social. Isso porque as categorias construídas a partir da perspectiva do risco se relacionam àqueles sujeitos considerados desviantes por possuírem modos não-normativos de viver, habitar e dispor de sua sexualidade. Dentro dessa perspectiva, o perigo igualase a tudo aquilo que é avesso à norma. Os serviços de saúde, assistência social e justiça, por exemplo, vão operar como gestores de riscos, pois colocam em ação estratégias biopolíticas de governo da população que agem a partir de uma preocupação preventiva. Nesse sentido, prevenir é rastrear riscos. A análise dos riscos passa a ser realizada em nome da proteção à vida (Reis, Guareschi \& Carvalho, 2014).

Além dos discursos científicos sobre os riscos relacionados ao mal funcionamento familiar, os saberes psi fazem proliferar definições sexistas sobre como devem ser os pais e mães de família. A figura materna ainda seria aquela que dispõe predominantemente das faculdades afetivas; já a figura paterna é definida como aquela a quem cabe a direção moral. Reis (2008) problematiza a forma como os especialistas declaram como instintivo o amor materno e os laços consanguíneos como naturalmente mais fortes do que todos os outros. A autora ressalta que, embora essas noções hegemônicas de família não tenham emergido de uma única vez e sejam o produto do embate de múltiplas forças e interesses, o que faz com que sofram modificações ao longo dos anos, a proliferação discursiva desses saberes normativos e sua repetição contínua mantêm o estatuto de verdade dessas noções.

O que vemos nos Processos é a demonstração de um esforço contínuo de manutenção de determinadas marcas identitárias, como se houvesse certo modo de 
expressão de uma identidade verdadeira do ser mãe e ser pai em relação à qual são comparadas as performances dos pais em questão. Ainda que tenha havido deslocamentos nos modelos conjugais, vemos o retrato de figuras que Reis (2008) descreve como híbridos de tradição e modernidade. Evidencia-se o quanto os materiais reproduzem concepções familiaristas e de gênero que restringem as possibilidades de ser sujeito dentro desses limites identitários e colocam as manifestações que estão para além desses modelos como patológicas e disfuncionais.

O pai paga a pensão aos filhos, é alcoolista e tem aparência e postura frágil. Os vizinhos denunciaram ao Conselho Tutelar que as crianças sofriam maus tratos por parte da mãe, e o pai era negligente. (Ofício do Conselho Tutelar)

\section{A função paterna ainda era um desafio para o} pai. Registra-se o falecimento da mãe nesse meio tempo. Os meninos apresentam vulnerabilidade interna e baixa autoestima. (Relatório do Abrigo)

Outra questão que evidencia a presença de certas concepções sobre os modos de ser pai e mãe é a das denominações utilizadas nos Processos Judiciais que fazem referência a "genitor" e "genitora", as quais se diferenciam das denominações "pai" e "mãe". O que fica colocado nessa diferenciação é que as relações que se dão entre esses genitores objetos da ação judicial e tutelar e suas proles não configuram as mesmas relações familiares que hoje reconhecemos como aquelas que devem estar presentes entre pais e filhos. Assim, é evidenciada a manutenção de expectativas naturalizadas acerca de modelos femininos, masculinos e familiares que continuam a reverberar no espaço social (Reis, 2008).

Estavam os jovens na casa de acolhimento por negligência do genitor. Em casa eram agredidos pela genitora, também dependente química. Foram internados e após retornaram para a rua, sem continuidade do tratamento ambulatorial. (Petição Inicial do MP)

Uma última questão que não pode deixar de ser mencionada é a que se refere à ausência do pai, expressão que algumas vezes se configura quase como uma categoria diagnóstica: "o adolescente sofre de ausência do pai". A associação do pai, ou da figura paterna, com as noções de autoridade, disciplina, ordem social, bastante potencializada pelo complexo edipiano da psicanálise, auxiliou a forjar a possibilidade de existir uma vinculação direta entre a ausência de quem exercesse essa função e suas consequências na vivência subjetiva de crianças e adolescentes, levando-os ao desenvolvimento de comportamentos delinquentes (dentre estes, está considerado o uso de drogas, uma vez que se configura como uma transgressão às normas). Alguns exemplos de estudos que legitimam essa relação podem ser encontrados ao lançarmos as palavras ausência paterna e delinquência ou ausência paterna e uso de drogas em ferramentas de busca de artigos científicos. A partir dessa ação, é possível identificar artigos como: Lago (2009), Função paterna e comportamentos delinquentes em rapazes adolescentes; Eizirik e Bergmann (2004), Ausência paterna e sua repercussão no desenvolvimento da criança e do adolescente: um relato de caso; Iglesias (2007), Desagregação familiar e delinquência infantojuvenil; Penso e Sudbrack (2004), Envolvimento em atos infracionais e com drogas como possibilidade para lidar com o papel de filho parental; Dell'Aglio, Santos e Borges (2004), Infração juvenil feminina: uma trajetória de abandonos; Freitas (2002), Adolescência, família e drogas: a função paterna e a questão dos limites, entre muitos outros.

Valente, Medrado e Lyra (2011), ao analisarem as produções acadêmicas sobre o tema da paternidade entre os anos de 1987 e 2009, evidenciam que é permanente a busca de uma verdade cientificamente comprovável acerca do ser pai na produção de saberes sobre a paternidade, principalmente a partir do campo psi, embora tenha havido mudanças ao longo dos anos. No estudo, os autores atentam para a forma com esses campos de saber, ao produzirem conhecimento, operam também na produção dos próprios modos de ser pai e mãe. Aqui, podemos acrescentar a produção de determinados modos de ser filho e "experienciar subjetivamente" as diferentes relações parentais com as quais interagem.

\section{CONSIDERAÇÕES FINAIS}

Ao longo dos Processos Judiciais, é possível acompanhar a forma como a família vai sendo patologizada pelos diferentes campos de saber. Essa desqualificação da família constitui-se em um verdadeiro extermínio feito pela ciência, em especial, pela Psicologia e pelo Serviço Social, de forma tão potente que pouco resta à família a não ser sua redução àquilo que é dito por esses especialistas e a desistência de sua função em nome do Estado, que passa a ser legitimado como aquele que sabe e pode dar proteção a crianças e adolescentes. Entretanto, ao acompanhar as crianças e adolescentes dentro das redes do Estado, 
é fácil perceber o quanto as instituições que criamos tampouco conseguem dar conta daquilo que a família foi acusada de fracassar.

Não se trata aqui de vitimizar as famílias, tanto quanto não se trata de desconsiderar a importância dos órgãos de proteção organizados por meio do Estado. A reflexão que nos propomos a fazer é sobre os efeitos desse modo de organização das ações do Estado, isto é, o que essa lógica do trabalho social tem produzido. Produz, conforme a análise dos Processos
Judiciais, a patologização da família, constrói modelos idealizados de como ser pai, mãe e filho que, em maior ou menor medida, família alguma consegue dar conta. Além desses efeitos micropolíticos, concretamente a desvinculação das crianças e adolescentes das suas famílias “desestruturadas" para inclusão racional desses sujeitos nas instituições do Estado, não em todos, mas em muitos casos, acaba se efetivando como mais um modo de expor esses sujeitos à desproteção e de deixálos disponíveis à criminalidade e ao uso de drogas.

\section{REFERÊNCIAS}

Brasil. Presidência da República. (1990). Lei 8.069. Estatuto da Criança e do Adolescente. Diário Oficial da República Federativa do Brasil. Brasília, 13 julho de 1990. Acessado em: 10 mar. 2014, de <http://www.planalto.gov.br/ ccivil_03/leis/L8069.htm>.

Brasil. Presidência da República. Casa Civil. (1988). Constituição da República Federativa do Brasil. Brasília: Senado Federal. Acessado em: 10 mar. 2014, de <http://www.planalto.gov.br/ccivil_03/Constituicao/ConstituicaoCompilado. $\mathrm{htm}>$.

Dell'Aglio, D., Santos, S., \& Borges, J. (2004). Infração Juvenil Feminina: uma trajetória de abandonos. Interação em Psicologia, 8(2), 191-198.

Donzelot, J. (1986). A Polícia das Famílias (2aㅡ ed.). Rio de Janeiro: Edições Graal.

Eizirik, M. \& Bergmann, D. (2004). Ausência paterna e sua repercussão no desenvolvimento da criança e do adolescente: um relato de caso. Revista Psiquiatria RS, 26(3), 330-336. http://dx.doi.org/10.1590/s0101-81082004000300010

Foucault, M. (2014). História da Sexualidade I: a vontade de saber (Obra originalmente publicada em 1988, traduzida por Maria Thereza da Costa Alburquerque e J.A. Guilhon Albuquerque (17ª ed.). Rio de Janeiro: Edições Graal.

Freitas, L. (2002). Adolescência, família e drogas: a função paterna e a questão dos limites. Rio de Janeiro: Mauad Editora.

Garland, D. (2008). A Cultura do Controle: crime e ordem social na sociedade contemporânea. Rio de Janeiro: Renavan.

Iglesias, F. (2007). Desagregação familiar e delinqüência infanto-juvenil: uma reflexão acerca das implicações da ausência paterna no comportamento dos filhos menores. Revista Eletrônica Jus Navigandi. Acessado em: mar. 2012, de $<$ http://jus.com.br/revista/texto/9502/desagregacao-familiar-e-delinquencia-infanto-juvenil $>$.

Lago, T. (2009). Função Paterna e Comportamentos Delinquente em Rapazes Adolescentes (Dissertação). Faculdade de Psicologia e de Ciência da Educação, Universidade de Lisboa.

Lemos, F. C. (2009). O Estatuto da Criança e do Adolescente em Discursos Autoritários. Fractal: Revista de Psicologia, 21(1), 137-150. http://dx.doi.org/10.1590/s1984-02922009000100011

Lemos, F. C., Nascimento, M. L., \& Scheinvar, E. (2010). Inquietações a respeito do acontecimento risco: crianças e jovens em foco. Revista do Ministério Público do Estado do Pará, 5(1), 91-102.

Nascimento, M. L. (2012). Abrigo, pobreza e negligência: percursos de judicialização. Psicologia e Sociedade, 24, 39-44. http://dx.doi.org/10.1590/S0102-71822012000400007

Penso, M. A. \& Sudbrack, M. F. (2004). Envolvimento em atos infracionais e com drogas como possibilidade para lidar com o papel de filho parental. Psicologia USP, 15(3), 29-54. http://dx.doi.org/10.1590/S0103-65642004000200003

Reis, E. F. (2008). Produzindo Mães e Pais de Família. In C. Coimbra, L. Ayres, \& M. L. Nascimento. Pivetes: encontros entre psicologia e o judiciário (pp. 167-176). Curitiba: Juruá Editora.

Reis, C. D. (2012). (Falência Familiar) + (Uso de Drogas) = Risco e Periculosidade - a naturalização jurídica e psicológica de jovens com medida de internação compulsória (Dissertação), Programa de Pós-Graduação em Psicologia Social e Institucional, Universidade Federal do Rio Grande do Sul, Porto Alegre, Brasil.

Reis, C. D., Guareschi, N. M. F., \& Carvalho, S. (2014) Sobre jovens drogaditos: as histórias de ninguém. Psicologia e Sociedade, 26(n.esp.), 68-78. http://dx.doi.org/10.1590/S0102-71822014000500008

Scheinvar, E., Nascimento, M. L., \& Lemos, F.C. (2014). Uma Análise do Acontecimento Crianças e Jovens em Risco. Psicologia e Sociedade, 26, 158-164. http://dx.doi.org/10.1590/S0102-71822014000100017

Valente, M. B., Medrado, B., \& Lyra, J. (2011). Ciência como dispositivo de produção da paternidade: análise de produções científicas brasileiras. Athenea Digital, 11(2), 57-72. 
Xavier. D. (2012). Comissão debate internação compulsória de viciados em drogas, que vivem nas ruas da cidade de São Paulo [Entrevista ao Portal de Notícias da Câmara Municipal de São Paulo]. Acessado em 10 mar. 2012, de <http://www. camara.sp.gov.br/index.php?option=com_content\&view=article\&id=5151 :comissao-debate-internacao-compulsoriade-viciados-em-drogas-que-vivem-nas-ruas-da-cidade-de-sao-paulo-\&catid=112:podcast\&Itemid=199>.

Young, J. (2002). A Sociedade Excludente: exclusão social, criminalidade e diferença na modernidade recente. Rio de Janeiro: Renan.

Autores:

CAROlina dos ReIS - Doutoranda em Psicologia Social e Institucional pela Universidade Federal do Rio Grande do Sul.

NeuZa Maria de FÁtima GuARESCHI - Docente do Programa de Pós-Graduação em Psicologia Social e Institucional da Universidade Federal do Rio Grande do Sul.

SAlo De CARVAlHO - Professor Adjunto da Faculdade Nacional de Direito, Universidade Federal do Rio de Janeiro.

\section{Endereço para correspondência:}

Carolina dos Reis

Rua Capaão da Canoa, 20/201 - Ipanema

CEP 91760-170 Porto Alegre, RS, Brasil

E-mail: carolinadosreis@gmail.com

Recebido em: 17.11 .14

Aceito em: 26.05.15 